Pak. j. sci. ind. res. Ser. B: biol. sci. 201457 (2) 81-85

\title{
Identification of Phytophthora Species on Cocoa Pods and Pod Husks Using Three Culture Media
}

\author{
Bello Marcus Oluyemi*a, Adejumo Timothy Olubisia ${ }^{a}$, Akinbobola Ayorinde Bunmi ${ }^{\text {a }}$ \\ and Oloye Femi Francis ${ }^{b}$ \\ ${ }^{a}$ Microbiology Department, Adekunle Ajasin University, PMB 001 Akungba Akoko, Ondo State, Nigeria \\ ${ }^{\mathrm{b} C h e m i s t r y ~ D e p a r t m e n t, ~ A d e k u n l e ~ A j a s i n ~ U n i v e r s i t y, ~ P M B ~} 001$ Akungba Akoko, Ondo State, Nigeria
}

(received December 30, 2012; revised March 20, 2014; accepted April 2, 2014)

\begin{abstract}
The objectives of this study were the development of three media from locally available materials for isolation of Phytophthora spp., from infected cocoa pods and pod husks samples and the identification of isolated Phytophthora spp., collected from four cocoa producing States in south-western part of Nigeria. The formulated media included tomato juice agar (TJA), cocoa beans agar (CBA) and cocoa pod and beans agar (CPBA). TJA supported the best pathogen growth followed by CBA and CPBA. Based on cultural and morphological characteristics, $P$. palmivora and $P$. megakarya were identified in infected cocoa pods and pod husks. These findings indicated an urgent need for strategies in the management of cocoa diseases in cocoa producing States in south-western Nigeria.
\end{abstract}

Keywords: cocoa pods, Phytophthora spp., P. palmivora, P. megakarya, pod rot, P. tropicalis, tomato juice agar

\section{Introduction}

Cocoa is one of the agricultural commodities that provide the highest foreign exchange earnings in Nigeria (Adejumo, 2005). Nigeria is placed $5^{\text {th }}$ with 174 thousand tonnes, which amounted to $4.6 \%$ of the world production in 2007 (ICCO, 2010). In Nigeria, cocoa production is concentrated in the rainforest across 'cocoa belt' region. The main cocoa producing States are Ondo, Osun, Ogun, Delta, Edo, Cross-rives and Akwa-Ibom and Ondo State, produceing over 50\% of the total annual national production (Oyekale et al., 2009; Adejumo, 2005).

Phytophthora spp., is the major pathogen that affects cocoa plant, although these species attack all parts of cocoa plant, the major economic loss is from infection of the pods. Pods or cherelles (immature pods) may be infected at any place on the surface, but infection is most often initiated at the tip or stem end (Evans et al., 2003). The disease causes a firm, spreading, chocolatebrown lesion that eventually covers the whole pod within 10-12 days of infection. The beans inside the pod may remain undamaged for several days after initial infection of the husk. In advanced infections, Phytophthora invades the internal pod tissues and causes discolouration and shrivelling of the cocoa beans

*Author for correspondence; E-mail: marc1759@yahoo.com
(Aragaki and Uchida, 2001). Diseased pods eventually become black and mummify. The pathogens also cause seedling blight in cocoa nurseries as a result of infection of the stem. Black pod disease (pod rot) is a major problem to cocoa production in Nigeria. The causative agents include P. palmivora, P. megakarya, and $P$. capsici. The most important species in Nigeria and the west Africa sub-region is P. megakarya (Opoku et al., 2007). Except for some species that are transmitted aerially, the spread of Phytophthora is mainly through infected soil, animals, water and plants and plant materials (Bawage et al., 2013). Phytophthora spp., grow slowly in vitro as compared with most fungi and bacteria. They can be isolated by plating diseased tissue onto selective medium consisting of $\mathrm{V}_{8}$ juice, corn meal, or potato dextrose agar as base medium and can be tested against different antibiotics. These antibiotics are: pimaricin, ampicillin, rifampicin, pentachloronitrobenzene (PCNB), and hymexazole (Kannwischer and Mitchell, 1978).

The objective of this research was to isolate and identify various Phytophthora spp., causing black pod disease of cocoa in four south-western States in Nigeria (Ondo, Ogun, Osun and Ekiti States), and to compare the growth rate of Phytophthora spp., on three different culture media that include tomato, cocoa and cocoa pod bean based media. 


\section{Materials and Methods}

Samples collection. The pod husks were randomly taken aseptically from husk piles of two weeks old, while fresh cocoa pods showing symptoms of black pod infections from trees were removed with sickle at two farms in each locations from two major cocoa producing farms each from Ogun, Osun, Ekiti State and three locations were collected in Ondo State, Nigeria. All samples were labelled appropriately and transported to the laboratory on ice in a cooler for organisms to remain viable and isolations from samples were made within $12 \mathrm{~h}$ of sampling.

Media formulation for isolation of Phytophthora. Tomato juice agar (TJA) was prepared by modifying methods of Adesemoye and Adedire (2005) and Bush et al. (2006). Fresh tomato fruit (215 g), were washed and blended using a house-hold blender (Phillips, UK). The tomato chyme was sieved into an Erlenmeyer flask to remove shaft. The sieved tomato chyme, $100 \mathrm{~mL}$ was placed into one litre clean Erlenmeyer flask, this was then made up to $230 \mathrm{~mL}$ by adding sterilised distilled water and $5.1 \mathrm{~g}$ of agar-agar was added. The formulation of the cocoa bean agar (CBA) and cocoa pod and bean agar (CPBA) followed similar step as TJA. Two mature cocoa pods (found free of infection) were obtained from the cocoa orchard. They were washed, broken open, and $215 \mathrm{~g}$ each of the pod with beans, beans only was mashed in a mortar separately and the same formulation rate as TJA was used. The mixtures were homogenised thoroughly. The $\mathrm{pH}$ was measured and adjusted to be 4.7 prior to sterilisation in an autoclave for $15 \mathrm{~min}$ at temperature of $121^{\circ} \mathrm{C}$ and $1.1 \mathrm{~kg} / \mathrm{cm}^{2}$ pressure. The sterilised media was allowed to cool to the temperature of about $45{ }^{\circ} \mathrm{C}$ and aseptically poured into sterilised petri dishes.

Inoculation and incubation. Cocoa pods and pod husks samples were washed with tap water and disinfected by dipping in $95 \%$ ethanol for $3 \mathrm{sec}$ in $10 \%$ sodium hypochloride for $30 \mathrm{sec}$ and again in $75 \%$ ethanol for $2 \mathrm{sec}$. The pods were rinsed three times in sterile distilled water to eliminate any trace of disinfectant. Aseptically, superficial tissues were removed, cuts of 3-4 mm size were made in three locations per pod and pod husks using a sterile scalpel and placed on the newly developed media with each sample having five replicates. The inoculated plates were then incubated at room temperature $\left(25^{\circ} \mathrm{C}\right)$ in the laboratory for $72 \mathrm{~h}$. The average diameters of growth (mean \pm SEM) of the culture were measured and recorded for 3 days at $24 \mathrm{~h}$ intervals and isolates were purified by transferring hyphal tips to new sterile agar plates (Adesemoye et al., 2014). Macroscopic observation of the culture was done. Microscopic examination of the sporangia was carried out by preparing slide mounts from the incubated culture plates. Data obtained were statistically analysed using Microsoft Excel.

\section{Results and Discussion}

Average diameters of growth with respect to the media used for pod husks samples after $72 \mathrm{~h}$ of incubation (Fig. 1) show that growth on TJA has highest average diameter of growth followed by the CBA and the least was observed on CPBA. This is the same for all locations except from Ilaro B in which the CBA shows more growth than the TJA and CPBA for the isolates from cocoa pod husks. While, average diameters of growth with respect to the media used for infected pod samples after $72 \mathrm{~h}$ of incubation (Fig. 2). The isolates from the infected cocoa pods show the highest average diameters of growth on TJA followed by CBA and CPBA in all locations except in isolates from Ilaro A, where CBA shows the highest average diameter of growth followed by TJA and CPBA after $72 \mathrm{~h}$ of incubation (Fig. 2). TJA, CBA and cocoa pod and CPBA supported the growth of Phytophthora spp., from infected pod and pod husks, with TJA culture showing the highest average diameter of growth followed by CBA. CPBA showed the least average diameters of growth for isolates from both, fresh pods and pod husks measured after $72 \mathrm{~h}$ of incubation. The hyphae on the TJA appeared whitish throughout the period of $72 \mathrm{~h}$ of incubation, while, those on the CBA and CPBA appeared whitish initially but turned brown/black after $48 \mathrm{~h}$ of incubation. With these three media, P. megakarya was isolated from all locations (pod and pod husks) in Ogun (Sagamu and Ilaro), Osun (Ife and Ilesha), Ondo (Akungba, Idanre and Ondo), while, P. palmivora was isolated from Ekiti (Imesi and Ikole) (Table 1).

The result of this study shows the effectiveness of the developed media as they helped in isolation of P. megakarya and P. palmivora from pod and pod husks in all sampling locations. The problem usually encountered in developing countries from the need to add several antibiotics to the conventional or popular medium used in Phytophthora studies may be circumvented. The clarified tomato juice agar, cocoa beans agar and cocoa pod and bean agar did not require antibiotics. The pattern of growth of the pathogen on the formulated 


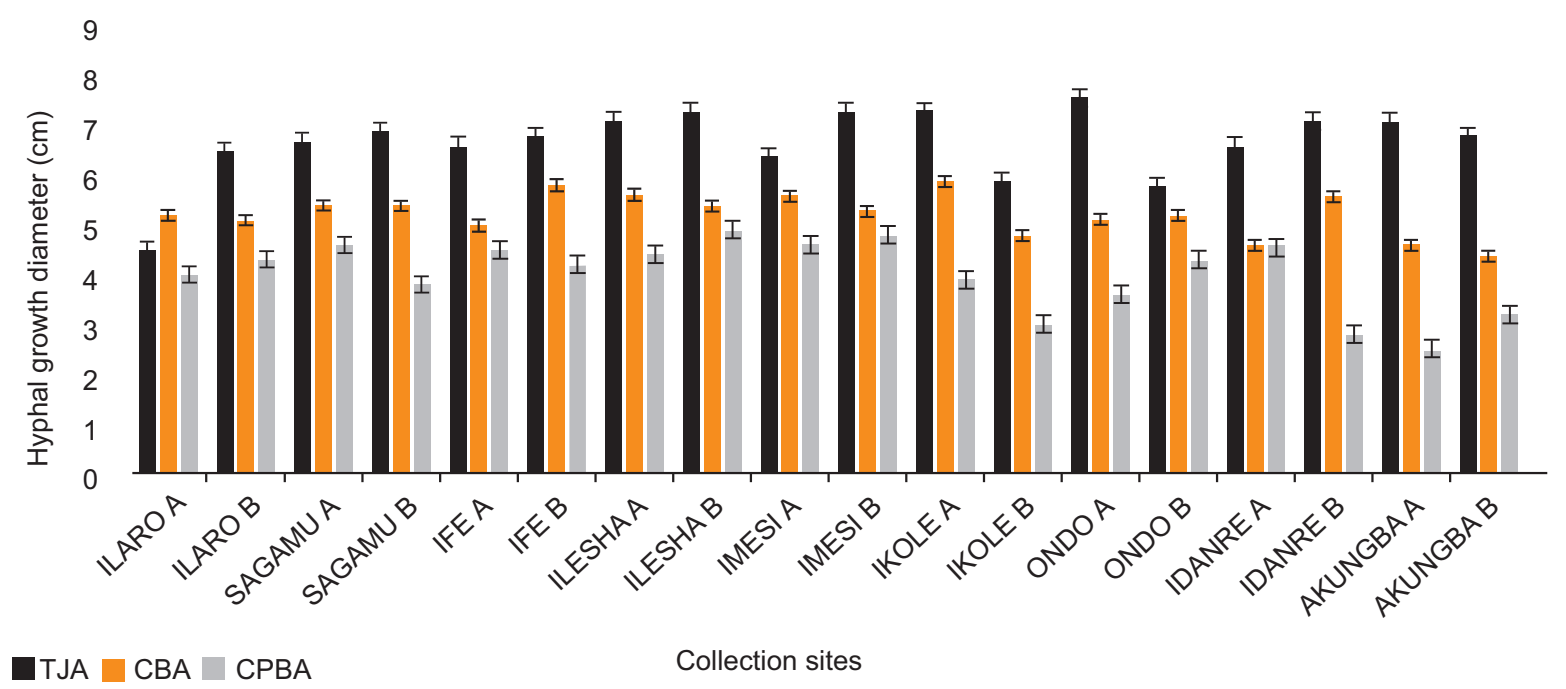

Fig. 1. Average diameters of growth with respect to the media used for pod husks samples after $72 \mathrm{~h}$ of incubation.

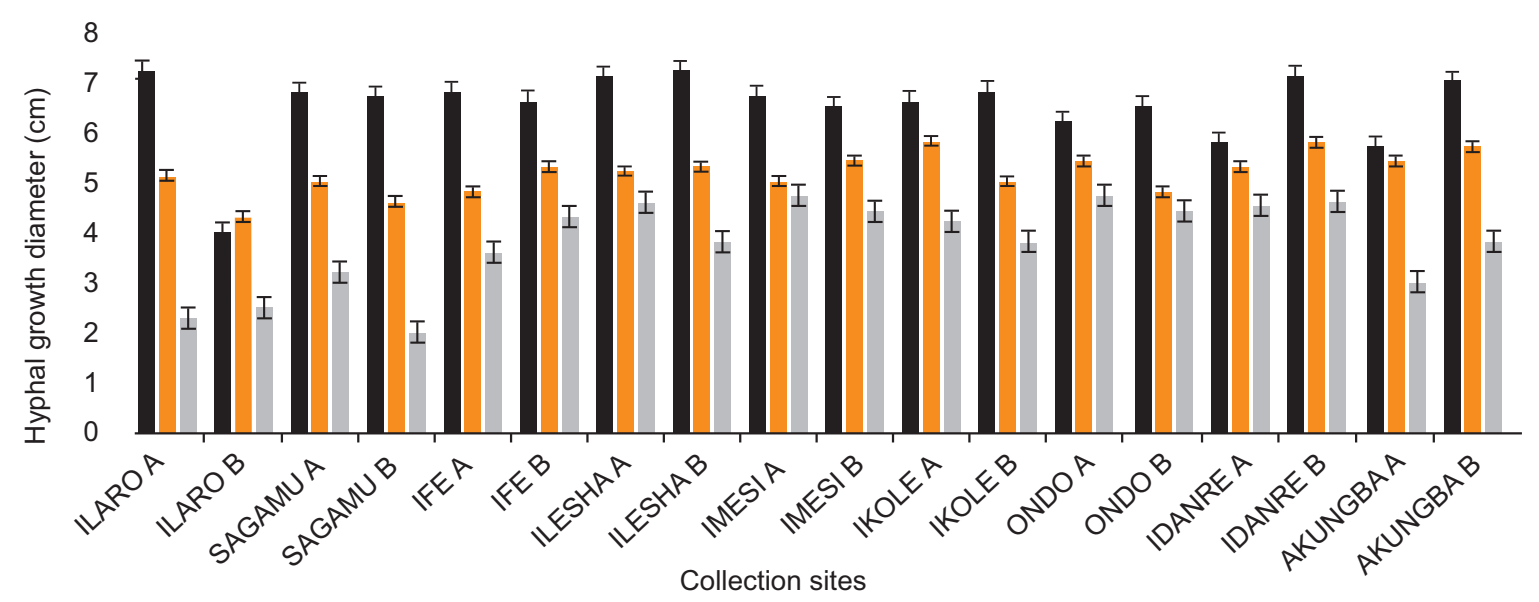

-TJA $\square$ CBA $\square$ CPBA

Fig. 2. Average diameters of growth with respect to the media used for fresh pod samples after $72 \mathrm{~h}$ of incubation.

media was different from the popular medium. On the conventional Phytophthora medium, P. megakarya grows relatively slower appearing whitish with appressed mycelial growth pattern, while on the newly formulated TJA, CBA and CPBA, the mycelial growth had aerial whitish appearance and relatively faster on the three media, which might be due to the absence of antibiotics on the three formulated media. Among these three media comparatively growth was slightly faster on TJA than CBA and CPBA after 72h (Fig. 1 and 2) and this may be as a result of the availability of high quantity of nutrients in tomato juice, which enhances the growth of Phytophthora in TJA media as compared to other media (Opoku et al., 2007). The TJA also supported good mycelial growth, abundant production of sporangia, many of which were ovoid and papillate, typical of P. palmivora. CBA and CPBA, though supporting a slightly lower radial growth, possessed mycological characteristics similar to those of TJA and therefore, can also be used to culture P. palmivora. Where, cocoa mucilage is not readily available, such as in the off cocoa season or in non-cocoa growing areas, the TJA can be used. Cocoa mucilage contains high levels of sugars, notably glucose and fructose, which are required for fungal growth and probably radial growth on the TJA higher because of its obviously higher sugar content (Opoku et al., 2007).

The slight differences in the growth pattern observed in Ilaro B (Fig. 1) and Ilaro A (Fig. 2) could be attributed to the environmental influence on the isolates (Griffith 
Table1. Sporangial morphological characteristics of samples from cocoa pods and husks

\begin{tabular}{|c|c|c|c|c|c|c|c|c|c|c|c|c|c|}
\hline \multirow[t]{2}{*}{ Sample } & \multicolumn{2}{|c|}{ Papillation } & \multicolumn{2}{|c|}{$\begin{array}{l}\text { Pedicel length } \\
(\mu \mathrm{m})\end{array}$} & \multicolumn{2}{|c|}{ Chlamydospores } & \multicolumn{2}{|c|}{$\begin{array}{l}\text { Branching } \\
\text { habit }\end{array}$} & \multicolumn{2}{|c|}{ Caducity } & \multicolumn{2}{|c|}{$\begin{array}{l}\text { Growth } \\
\text { appearance }\end{array}$} & \multirow[t]{2}{*}{$\begin{array}{l}\text { Probable } \\
\text { organisms }\end{array}$} \\
\hline & Pod & Husk & Pod & Husk & Pod & Husk & Pod & Husk & Pod & Husk & Pod & Husk & \\
\hline Sagamu A & + & + & 25 & 30. & - & - & - & - & - & - & PP. & PP & P. Megakarya \\
\hline Sagamu B & + & + & 22 & 25 & - & - & - & - & - & - & PP & PP & P. megakarya \\
\hline Ilaro A & + & + & 28 & 45. & - & - & - & - & - & - & PP & PP & P. megakarya \\
\hline Ilaro B & + & + & 40 & 40 & - & - & - & - & - & - & PP & PP & P. megakarya \\
\hline Ife A & + & + & 32 & 28 & - & - & - & - & - & - & PP & PP & P megakarya \\
\hline Ife B & + & + & 41 & 33 & - & - & - & - & - & - & PP & PP & P. megakarya \\
\hline Ilesha A & + & + & 36 & 43 & - & - & - & - & - & - & PP & PP & P. megakarya \\
\hline Ilesha B & + & + & 30 & 26 & - & - & - & - & - & - & PP & PP & P. megakarya \\
\hline Ondo A & + & + & 27 & 34 & - & - & - & - & - & - & PP & PP & P. megakarya \\
\hline Ondo B & + & + & 36 & 38 & - & - & - & - & - & - & PP & PP & P. megakarya \\
\hline Idanre A & + & + & 40 & 42 & - & - & - & - & - & - & PP & PP & P. megakarya \\
\hline Idanre B & + & + & 44 & 41 & - & - & - & - & - & - & PP & PP & P. megakarya \\
\hline Akungba A & + & + & 34 & 39 & - & - & - & - & - & - & PP & PP & P. megakarya \\
\hline Akungba B & + & + & 38 & 33 & - & - & - & - & - & - & PP & PP & P. megakarya \\
\hline Imesi A & + & + & 4 & 3 & + & + & - & - & + & + & SS & SS & P. palmivora \\
\hline Imesi B & + & + & 4 & 4 & + & + & - & - & + & + & SS & SS & P. palmivora \\
\hline Ikole A & + & + & 4 & 3 & + & + & - & - & + & + & SS & SS & P. palmivora \\
\hline Ikole B & + & + & 3 & 3 & + & + . & - & - & + & + & SS & SS & P. palmivora \\
\hline
\end{tabular}

Legend; + = present; - = absent; $\mathrm{PP}$ = powdery; $\mathrm{SS}$ = stellate.

and Jones, 1997). The results also indicated that P. megakarya is the commonest specie of Phytophthora found in pod and pod husks in all locations, where samples were collected i.e., Ogun, Osun and Ondo State, while P. palmivora was found in all the locations, where samples were collected in Ekiti State (Table1). The classification and identification were based on the following sporangial morphological characteristics by Griffith and Jones (1997). P. palmivora produces large chlamydospores and is easily distinguished from $P$. citrophthora and P. nicotinae by its caducous sporangia. Comparison of sporangial pedicel length allows easy discrimination of $P$. palmivora and $P$. tropicalis. Pedicels of $P$. palmivora are short at $<5 \mu \mathrm{m}$ as shown in Fig. 3, whereas, the pedicel of P. tropicalis are much longer being 16 to $120 \mu \mathrm{m}$. Only P. tropicalis have an umbellate branching habit (Hong et al., 2006). It is possible to distinguish $P$. palmivora and P. megakarya on the basis of sporangial morphology. P. palmivora have smaller pedicels and papillae on their sporangial, as well as macroscopic features, such as lesions morphology, P. megakarya lesions have a more powdery appearance on culture, while $P$. palmivora generally, has a stellate appearance on media culture as this is in agreement with Griffith and Jones (1997). Combining the use of these media with molecular detection methodology will significantly, aid the isolation and identification of Phytophthora spp., and this may help in control and eradication of Phytophthora spp.,

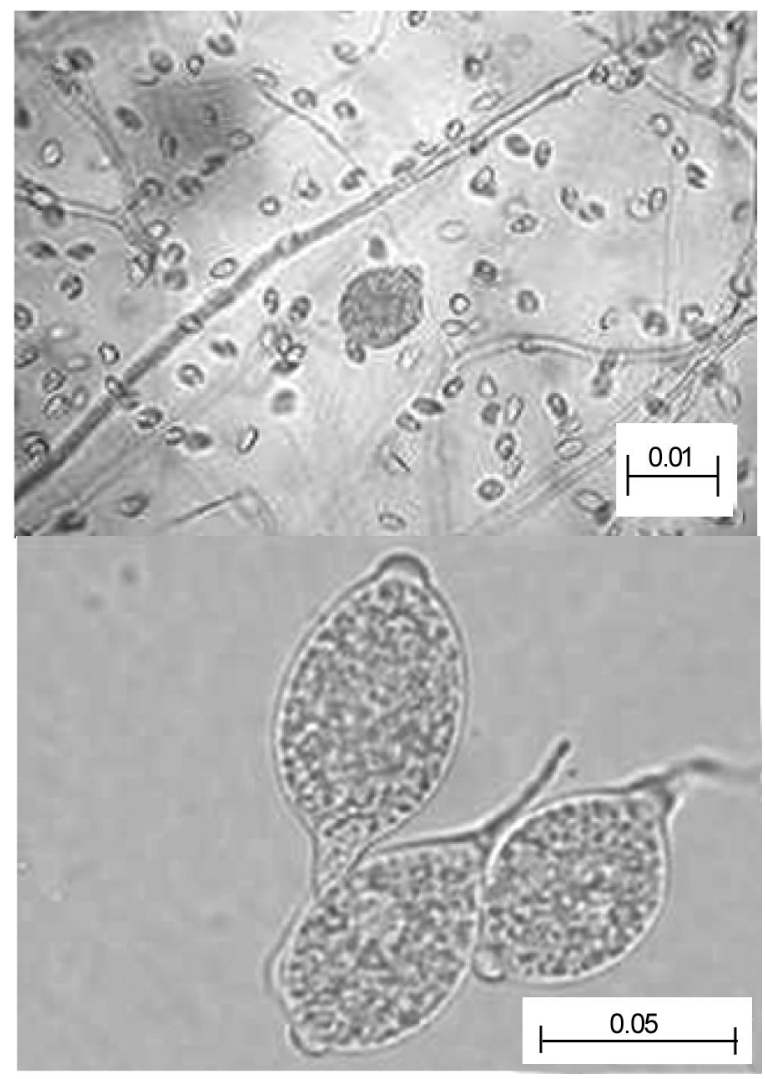

Fig. 3. The photomicrograph showing the spores of the Phytophthora palmivora, released from the sporangium (left) and sporangia with papillae (right) (Micron marker represent $0.01 \mu \mathrm{m}$ and $0.05 \mu \mathrm{m})$. 
infection of cocoa. Media from both, the CBA and CPBA seeds supported good aerial mycelial growth and sporulation but these media were not clear and need to be studied further to improve their clarity. Because both CBA and CPBA supported abundant production of the typical ovoid, papillate sporangia, they are recommended in studies, where such sporangia are needed in large quantities.

\section{References}

Adesemoye, A.O., Mayorquin, J.S., Wang, D.H., Twizeyimana, M., Lynch, S.C., Eskalen, A. 2014. Identification of species of Botryosphaeriaceae causing Bot gummosis in citrus in California. Plant Disease, 98: 55-61.

Adesemoye, A., Eskalen, A., Faber, B., O’Connell, N. 2010. Multiple Botryosphaeria species causing 'Do thiorella' gummosis in citrus. Citrograph, 2: 3234.

Adesemoye, A.O., Adedire, C.O. 2005. Use of cereals as basal medium for the formulation of alternative culture media for fungi. World Journal of Microbiology and Biotechnology, 21: 329-336.

Adejumo, T.O. 2005. Crop protection strategies for major diseases of cocoa, coffee and cashew in Nigeria. African Journal of Biotechnology, 4: 143-150.

Aragaki, M., Uchida, J.Y. 2001. Morphological distinctions between Phytophthora capsici and P. tropicalis sp. Mycologia, 93: 137-145.

Bawage, S., Nerkar, S., Kumar, A., Das, A. 2013. Morphological and molecular description of Phytophthora insolita isolated from citrus orchard in India. Journal of Mycology, Article ID 247951, 7 pp., http://dx. doi.org/ 10.1155/ 2013/247951.

Evans, H.C., Holmes, K.A., Reid. A.P. 2003. Phylogeny of the frosty pod rot of pathogen of cocoa. Plant Pathology, 52: 476-485.

Griffith, G.W., Jones, T.A.H. 1997. The development of a PCR based diagnostic test to distinguish between the black pod pathogen Phytophthora palmivora and P. megakarya. Final Report to the $B C C C A, 19$ pp.

Hong, C.X., Bush, E.A., Stromberg, E.L., Kong, P., Richardson, P.A. 2006. Illustration of key morphological characteristics of Phytophthora species identified in virginia nursery irrigation water. Plants Health Progress, Doi: 10.1094/ PzhP-2006-062101-Rs. http://www.plant management. org/php/ default.asp.

ICCO, 2010. International Cocoa Organization (www.icco.org).

Kannwischer, M. E., Mitchell, D.J. 1978. The influence of a fungicide on the epidemiology of black shank of tobacco. Phytopathology, 68: 1760-1765.

Opoku, I.Y., Assuah, M.K., Aneani, F. 2007. Management of black pod disease of cocoa with reduced number of fungicide application and crop sanitation. African Journal of Agricultural Research, 2: 601-604.

Oyekale, A.S., Bolaji, M.B., Olowa, O.W. 2009. The effect of climate change on cocoa and vulnerability assessment in Nigeria. Agricultural Journal, 4: 77-85. 